\title{
Leucemia agresiva de células natural killer en un paciente pediátrico
}

\author{
Elianneth Rey-Helo ${ }^{1 *}$, Rubén D. Pérez-Velásquez ${ }^{2}$ y Deyanira Cortés-Alva ${ }^{3}$ \\ ${ }^{1}$ Servicio de Oncología Pediátrica; ${ }^{2}$ Servicio de Patología; ${ }^{3}$ Servicio de Oncología. Hospital del Niño DIF (Sistema Nacional para el Desarrollo \\ Integral de la Familia). Hidalgo, México
}

\begin{abstract}
Resumen
Introducción: Las neoplasias de células natural killer (NK) son poco frecuentes y representan $<5 \%$ de todas las neoplasias linfoides. Comprometen diferentes entidades clínicas, como la leucemia de células NK, que es una neoplasia hematológica altamente agresiva con un pronóstico precario, que se presenta en hombres jóvenes y se observa con mayor frecuencia en ascendencia asiática. El virus de Epstein-Barr (VEB) parece estar relacionado con la patogenia de esta leucemia. Caso clínico: Se presenta el caso de un paciente de sexo masculino de 1 año y 7 meses de edad, quien inició su padecimiento con síndrome anémico, febril, infiltrativo e hiperleucocitosis. En el aspirado de médula ósea se detectaron blastos de morfología L2 (96\%), inmunofenotipo CD56 (80.87\%) y desoxinucleotidil transferasa terminal (84.11\%). En la biopsia de médula ósea se identificó $C D 2^{+}$membranoso, $C D 3^{+}$citoplásmico y $C D 56^{+}$membranoso; la serología para VEB fue positiva. El paciente recibió dos esquemas diferentes de quimioterapia basados en metotrexato, ifosfamida, etopósido, dexametasona y L-asparaginasa, y se documentó remisión parcial. Actualmente, se encuentra vivo con la enfermedad. Conclusiones: La leucemia de células NK es rara en adultos jóvenes, pero aún más en pacientes en edad pediátrica. Además, es de muy difícil tratamiento, ya que solo se cuenta con algunos reportes de casos, la sobrevida es de semanas a meses y las oportunidades de tratamiento se limitan. Recientemente, se ha evidenciado la utilidad del trasplante de médula ósea alogénico o células de cordón umbilical, y se ha logrado una sobrevida a 2 años. Las posibilidades terapéuticas en estos pacientes se encuentran en estudio. Se espera lograr en un futuro cercano la remisión completa y sobrevida a 5 años.
\end{abstract}

Palabras clave: Leucemia. Pediátrico. Células asesinas naturales. Pancitopenia.

\section{Agressive NK-cell leukemia in a pediatric patient}

\section{Abstract}

Background: Natural killer (NK) cell neoplasms are rare and represent $<5 \%$ of all lymphoid neoplasms. They involve different clinical entities, of which one is NK cell leukemia, a highly aggressive hematologic neoplasm with poor prognosis that presents in young men and is more frequently seen in Asian descent. Epstein-Barr virus (EBV) seems to be related to the pathogenesis. Case report: $A$ male patient of 1 year and 7 months of age, who began his condition with anemic, febrile, infiltrative syndrome and hyperleukocytosis is described. Bone marrow aspirate showed L2 morphology blasts (96\%), CD56 (80.87\%) and terminal deoxynucleotidyl transferase (84.11\%) immunophenotype. Bone marrow biopsy showed membranous CD2+,

Disponible en internet: 05-07-2019

Fecha de recepción: 25-01-2019 Fecha de aceptación: 06-03-2019 DOI: 10.24875/BMHIM 19000089
Bol Med Hosp Infant Mex 2019;76:188-192

www.bmhim.com 
cytoplasmic CD3+ and membranous CD56+; serology positive to EBV. The patient received two different chemotherapy schemes based on methotrexate, ifosfamide, etoposide, dexamethasone and L-asparaginase, which resulted in partial remission. Currently, the patient lives with the disease. Conclusions: NK cells leukemia is rare in young adults, but even more in pediatric patients, for which it is very difficult to treat because only a few cases have been reported in the literature, the survival varies from weeks to months and the chances of treatment are limited. Recently, the usefulness of allogeneic bone marrow transplantation or umbilical cord cells has been demonstrated, achieving a 2-year survival. The therapeutic possibilities in these patients are under study. In the near future, we hope to achieve the complete remission of the disease and a 5-year survival.

Key words: Leukemia. Pediatrics. Natural killer cells. Pancytopenia.

\section{Introducción}

Las neoplasias de células natural killer (NK) (también conocidas como células asesinas naturales) son entidades poco frecuentes que representan $<5 \%$ de las neoplasias linfoides y comprometen diferentes entidades clínicas. La Organización Mundial de la Salud, en su clasificación de 2008 de tumores hematopoyéticos $y$ tejidos linfoides, identifica tres enfermedades originadas de las células NK maduras: linfoma extranodal de células NK/T, linfoma nasal de células NK y leucemia agresiva de células $\mathrm{NK}^{1}$. La principal incidencia de esta última se concentra en países de Asia Oriental y América del Sur, donde se ha correlacionado estrechamente con la infección por el virus de Epstein-Barr (VEB).

La leucemia agresiva de células NK fue descrita originalmente por Fernández, et al. (1986) en un paciente de 70 años de edad, con padecimiento de abdomen agudo, que presentó posteriormente síndrome febril, diátesis hemorrágica y muerte ${ }^{2}$.

Este tipo de leucemia se caracteriza por una proliferación clonal de linfocitos grandes con gránulos CD3- CD56 $^{+}$. Clínicamente, los pacientes presentan principalmente fiebre, además de ictericia, linfadenopatías, hepatoesplenomegalia, células leucémicas en sangre periférica y citopenias. Generalmente, el pronóstico es malo y la mayoría de los pacientes muere en los primeros 2 meses a partir del diagnóstico. Frecuentemente, es posible demostrar la integración de secuencias genómicas del VEB ${ }^{3}$. Las alteraciones citogenéticas involucradas han sido escasamente caracterizadas: se han reportado deleciones en los cromosomas $6 \mathrm{q}, 11 \mathrm{q}$, $13 q$ y $17 p$, asociadas con la iniciación y progresión en el proceso oncogénico ${ }^{4}$. La enfermedad es típicamente quimiorresistente, lo cual se explica particularmente por la resistencia múltiple a fármacos codificada genéticamente por la glicoproteína $\mathrm{P}$ en la membrana celular, que excreta varios agentes citotóxicos como alcaloides de la vinca y antraciclinas. El tratamiento se basa en la administración de metotrexato, etopósido e ifosfamida de inicio, seguido del trasplante alogénico de células progenitoras hematopoyéticas, en caso de lograr la remisión de la enfermedad ${ }^{5}$.

\section{Caso clínico}

Se trata de un paciente de sexo masculino de 1 año y 7 meses de edad, que inició su padecimiento 3 meses antes de su ingreso en la institución, con presencia de palidez de tegumentos, fiebre intermitente, picos febriles de 38 a $40{ }^{\circ} \mathrm{C}$ que duraban 4 horas, dolor óseo, astenia y adinamia. Ante la exploración física, se detectaron adenomegalias submandibulares, soplo ocular, ruidos cardíacos con presencia de soplo sistólico grado II/VI en el segundo espacio intercostal izquierdo y hepatoesplenomegalia. Los resultados de los estudios de laboratorio (biometría hemática) fueron hemoglobina $3.1 \mathrm{~g} / \mathrm{dl}$, hematocrito $10 \%$, velocidad corpuscular media $85.3 \mathrm{fl}$, leucocitos $113,100 / \mathrm{mm}^{3}$, neutrófilos $0 \%$, linfocitos $16 \%$, blastos $84 \%$, plaquetas $224,000 / \mathrm{mm}^{3}$. El resto de los resultados de laboratorio no mostraron alteraciones. Por anemia grave, se realizó transfusión por recambio. Posteriormente, el paciente presentó síndrome de lisis tumoral, y se le implementó manejo basado en soluciones de hiperhidratación (solución glucosada al 5\% + bicarbonato de sodio), alopurinol, medidas antihiperkalémicas y controles de laboratorio. En la radiografía de tórax no se observó ensanchamiento mediastinal. Se realizó aspirado de médula ósea, donde se encontró celularidad aumentada, megacariocitos ausentes y blastos de morfología L2 (96\%), inmunofenotipo con presencia de CD56 (80.87\%), CD34 (35.16\%) y desoxinucleotidil transferasa terminal (84.11\%) (Fig. 1), índice de DNA de 1.18 y reacción en cadena de la polimerasa con transcriptasa reversa negativa. En el estudio de líquido cefalorraquídeo no se encontraron blastos (SNC 1). Se administró quimioterapia intratecal profiláctica. No se realizó cariotipo en búsqueda de alteraciones cromosómicas, como secuenciación masiva, por falta de recursos y sitio de referencia a nivel nacional para realizar la búsqueda 


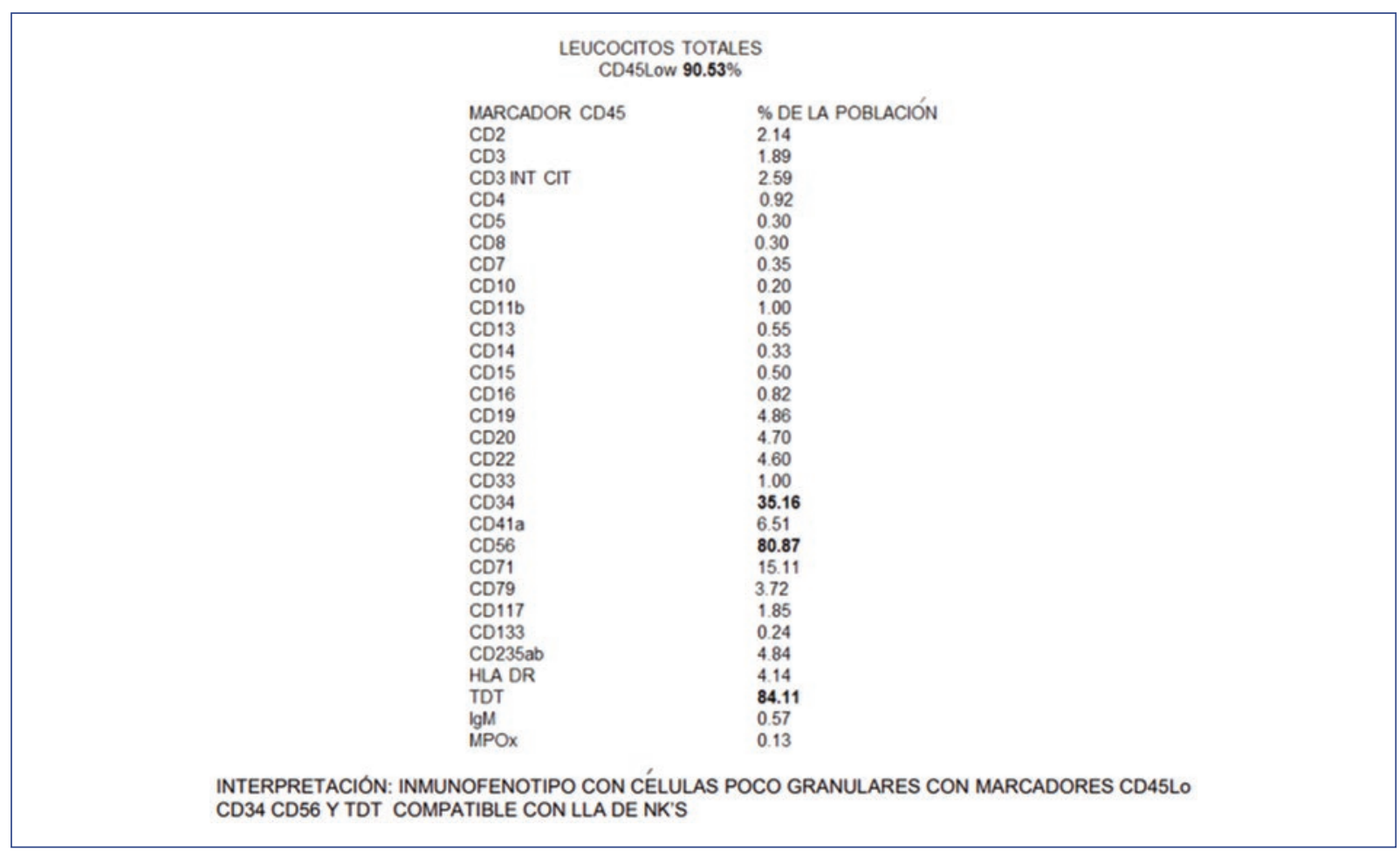

Figura 1. Inmunofenotipo de la médula ósea.

CD3 INT CIT: CD3 citoplásmico; HLA-DR: antígeno leucocitario humano; LLA: leucemia linfoblástica aguda; MPO: mieloperoxidasa; NK: natural killer; TDT: desoxinucleotidil-transferasa terminal.

intencionada. En el análisis serológico para el VEB se identificó antígeno (ag) temprano inmunoglobulina (lg) $\mathrm{G}$ (EA-lgG) $14.4 \mathrm{U} / \mathrm{ml}$, ag capsular IgG (VCA-lgG) $650 \mathrm{U} /$ $\mathrm{ml}$, ag capsular IgM (VCA-lgM) $40.2 \mathrm{U} / \mathrm{ml}$, ag nuclear IgG (EBNA-lgG) $106 \mathrm{U} / \mathrm{ml}$. Se inició tratamiento basado en el protocolo MIED ${ }^{6}$ : altas dosis de metotrexato $(5,000 \mathrm{mg} /$ $\mathrm{m}^{2} /$ día, infusión de $24 \mathrm{~h}$ i.v. en el día uno), ácido folínico $\left(15 \mathrm{mg} / \mathrm{m}^{2} /\right.$ dosis, iniciando a la hora 36 del metotrexato por cinco dosis i.v.), etopósido $\left(200 \mathrm{mg} / \mathrm{m}^{2} /\right.$ día en $3 \mathrm{~h}$ en los días 2-4 i.v.), ifosfamida (2,000 $\mathrm{mg} / \mathrm{m}^{2} /$ día en $1 \mathrm{~h}$ en los días 2-4) + mesna (500 mg/m²/dosis i.v. cada 6 h), dexametasona $\left(40 \mathrm{mg} / \mathrm{m}^{2} /\right.$ dosis cada $8 \mathrm{~h}$ por 12 dosis i.v., iniciando en el día uno). El paciente presentó choque séptico posterior al ciclo de quimioterapia. Se realizaron cultivos y se inició terapia con antibióticos intravenosos; no se reportó aislamiento del agente etiológico. Después del primer ciclo de quimioterapia, se realizaron estudios de evaluación, y se documentó remisión clínica y hematológica. La remisión morfológica no fue evaluable, debido a que el aspirado de médula ósea se encontró hipocelular, por lo cual se decidió realizar biopsia de médula ósea. En espera del resultado de patología, se administró metotrexato intramuscular $\left(10 \mathrm{mg} / \mathrm{m}^{2} / \mathrm{dosis}\right.$ semanal durante cinco semanas) ${ }^{7}$. Se obtuvo el reporte de la biopsia de médula ósea positiva para infiltración por células neoplásicas con inmunofenotipo CD2 ${ }^{+}$en el 15\%, $\mathrm{CD}^{+}$citoplásmico en el $15 \%$ y $\mathrm{CD}^{2} 6^{+}$en el $25 \%$ de la población celular y proteína latente de membrana negativo (Fig. 2). No se encontró genoma de VEB. Se documentó la respuesta parcial con el resultado de la biopsia de médula ósea, pero el paciente presentó nuevamente blastos (células leucémicas) en sangre periférica a las 6 semanas, por lo que se realizó una tomografía de cráneo en busca de linfoma centro nasal, sin hallazgos clínicos. Se decidió iniciar la segunda línea de tratamiento basado en el protocolo SMILE ${ }^{8}$ : altas dosis de metotrexato (5,000 mg/ $/ \mathrm{m}^{2} /$ día, infusión de 24 h i.v. en el día uno), ácido folínico $\left(15 \mathrm{mg} / \mathrm{m}^{2} /\right.$ dosis i.v. iniciando a la hora 36 del metotrexato por cinco dosis), etopósido (100 mg/ $/ \mathrm{m}^{2} / \mathrm{día}$ i.v. en $3 \mathrm{~h}$ en los días 2-4), ifosfamida $\left(1,500 \mathrm{mg} / \mathrm{m}^{2} / \mathrm{día}\right.$ en $1 \mathrm{~h}$ en los días $2-4)+$ mesna $\left(500 \mathrm{mg} / \mathrm{m}^{2} /\right.$ dosis i. v. cada $6 \mathrm{~h})$, dexametasona $\left(40 \mathrm{mg} / \mathrm{m}^{2} /\right.$ dosis i.v. cada $8 \mathrm{~h}$ en los días 2-4), L-asparaginasa $\left(6,000 \mathrm{U} / \mathrm{m}^{2}\right.$ en los días $8,10,12,14,16,18$ y 20$)$. Este protocolo ha tenido resultados favorables en pacientes con linfoma nasal NK. El paciente presentó toxicidad hematológica posterior al ciclo de segunda línea; persistió con pancitopenia y blastos en sangre periférica. Por presentar respuesta parcial al protocolo MIED, se decidió indicar un segundo ciclo de este, con el objetivo de lograr la remisión para enviar 


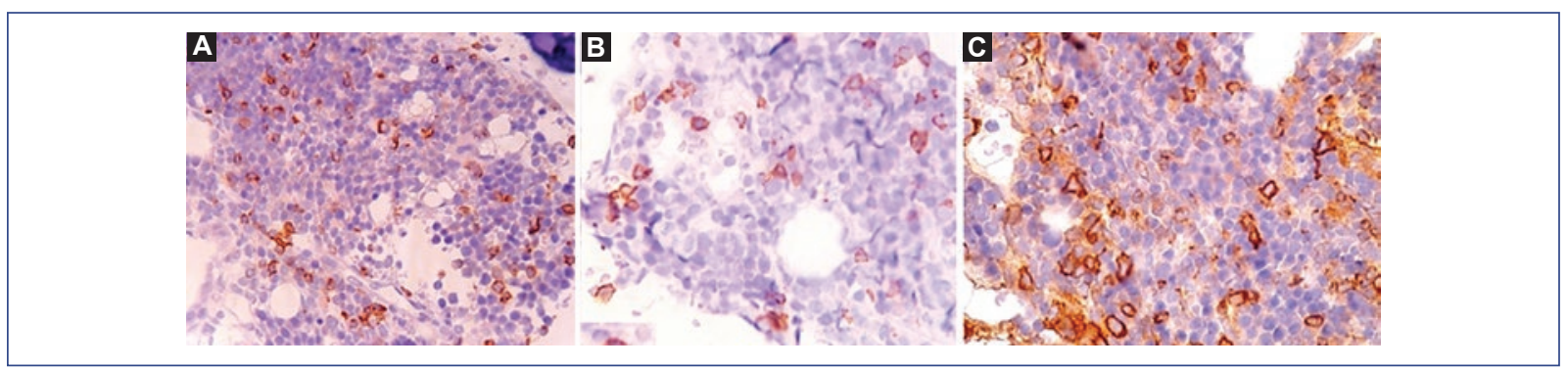

Figura 2. Inmunohistoquímica en biopsia de médula ósea: CD2+ membranoso (A), CD3+ citoplásmico (B) y CD56 membranoso (C).

a trasplante de células progenitoras hematopoyéticas haploidéntico (donador materno). Al no lograrse la remisión, se decidió enviar al paciente al programa de cuidados paliativos, pero los padres decidieron buscar una segunda opinión. Hasta el momento, el paciente se encuentra vivo con la enfermedad.

\section{Discusión}

La leucemia agresiva de células NK es una enfermedad rara, con un pronóstico extremadamente sombrío y sobrevida de semanas a pocos meses. Afecta principalmente a personas jóvenes, con predominio del sexo masculino. En este trabajo, se reporta un caso de trastorno linfoproliferativo de células NK, en México, en un paciente menor de 2 años, quien solicitó alta voluntaria al mes del ingreso ${ }^{9}$. Dada la escasa incidencia de esta variedad de linfomas/leucemias, la información disponible en la literatura actualmente se limita a reportes de casos clínicos y tratamientos empíricos basados en la alta agresividad de estos tumores, a falta de ensayos controlados y aleatorizados.

El padecimiento inicial del paciente simulaba una leucemia linfoblástica aguda, ya que presentó síndrome febril, anémico, infiltrativo e hiperleucocitosis (leucocitos $>100,000 / \mathrm{mm}^{3}$ ), edad de incidencia y presencia de blastos linfoides de morfología L2 (blastos grandes, heterogéneos, cromatina variable, presencia de más de un nucléolo, cantidad de citoplasma moderadamente abundante) en el aspirado de médula ósea. Se detectó inmunofenotipo $\mathrm{CD}^{+}, \mathrm{sCD}^{-}$(superficie), $\mathrm{CCD}^{+}$(citoplásmico), $\mathrm{CD}^{+} 6^{+}$y $\mathrm{CD}^{-} 6^{-}$(este último ausente tanto por inmunofenotipo como inmunohistoquímica), lo cual coincide con lo reportado en la literatura para leucemia agresiva de células NK, por lo que se orientó el diagnóstico con este hallazgo.

Dentro de los diagnósticos diferenciales, se descartó un linfoma centro-nasal de células NK con infiltración a médula ósea mediante una tomografía de cráneo que no presentó alteración. Cabe mencionar que, para confirmar dicho diagnóstico, se debe encontrar una médula ósea con $<20 \%$ de blastos, característica clínica que el paciente no presentó, confirmándose una leucemia aguda. Estos resultados orientaron al diagnóstico reportado. El caso fue evaluado por la institución de origen, dos instituciones de tercer nivel y una institución a nivel internacional.

El tratamiento descrito en la literatura reporta metotrexato, ifosfamida y etopósido ${ }^{10}$ como buena terapia inicial, por lo cual se utilizó el protocolo MIED (además de que el paciente presentaba resistencia múltiple a fármacos). Se obtuvo una respuesta parcial (disminución de la cuenta de blastos en la médula ósea $>50 \%$, biometría hemática sin citopenias y paciente sin datos clínicos de enfermedad). Posteriormente, se inició la administración de metotrexato intramuscular semanal durante 6 semanas. Sin embargo, el paciente presentó nuevamente actividad de la enfermedad, evidenciada por presencia de blastos en sangre periférica. La eficacia del metotrexato intramuscular se ha documentado en padecimientos crónicos linfoproliferativos benignos al actuar como agente inmunosupresor y no en leucemias agudas como la de este caso.

Se ha documentado la eficacia de la L-asparagina$\mathrm{sa}^{11}$ en estas entidades clínicas, por lo que se decidió utilizar el protocolo SMILE, pues al incluir un fármaco diferente, se podría evadir la resistencia presentada con los otros fármacos. Por esta razón, no se optó por un protocolo de rescate como el IDA-FLAG: fludarabina, citarabina, factor estimulante de colonias de granulocitos e idarrubicina. Se documentó nula actividad y, además, las dosis administradas de los otros fármacos diferentes a la L-asparaginasa eran menores al primer protocolo utilizado.

La enfermedad fue evidenciada nuevamente por la presencia de blastos en sangre periférica y hepatomegalia, por lo que se decidió administrar un segundo ciclo MIED basándose en la respuesta parcial inicial. Existe 
controversia en la literatura acerca del uso de antracíclicos ${ }^{11,12}$, debido a la resistencia que presentan, por lo que no se consideró como opción de tratamiento.

Se han documentado tratamientos exitosos en pacientes con las mismas características que el presente caso con trasplante alogénico o de cordón umbilical. Ebihara, et al. reportaron un protocolo de acondicionamiento con irradiación corporal total (12 Gy en cuatro fracciones por 2 días en los días -9 y -8), tiotepa (150 mg/m² x 2 en los días -7 y -6) y ciclofosfamida (60 mg/kg x 2 en los días -4 y -3), con presencia de enfermedad y posteriormente trasplante, y tuvieron éxito ${ }^{13}$. Este protocolo se considera como una posibilidad para este paciente en un tercer nivel de atención. En este caso, el tratamiento definitivo era la realización de un trasplante haploidéntico, con la administración previa de quimioterapia para la lograr la remisión.

\section{Responsabilidades éticas}

Protección de personas y animales. Los autores declaran que para esta investigación no se han realizado experimentos en seres humanos ni en animales.

Confidencialidad de los datos. Los autores declaran que han seguido los protocolos de su centro de trabajo sobre la publicación de datos de pacientes.

Derecho a la privacidad y consentimiento informado. Los autores han obtenido el consentimiento informado de los pacientes o individuos referidos en el artículo. Este documento obra en poder del autor de correspondencia.

\section{Conflicto de intereses}

Los autores declaran no tener ningún conflicto de intereses.

\section{Financiamiento}

Ninguno.

\section{Agradecimientos}

A los padres del paciente, por permitir el tratamiento y su confianza. Al Dr. Rubén Darío Pérez Velásquez, por su ayuda en el diagnóstico y seguimiento del paciente.

\section{Bibliografía}

1. Ishida F, Kwong YL. Diagnosis and management of natural killer-cell malignancies. Expert Rev Hematol. 2010;3:593-602.

2. Fernandez LA, Pope B, Lee C, Zayed E. Aggressive natural killer cell leukemia in an adult with establishment of an NK cell line. Blood. 1986;67:925-30

3. Greer JP, Mosse CA. Natural killer-cell neoplasms. Curr Hematol Malig Rep. 2009;4:245-52.

4. Wong KF, Zhang YM, Chan JK. Cytogenetic abnormalities in natural killer cell lymphoma/leukaemia-is there a consistent pattern? Leuk Lymphoma. 1999;34:241-50.

5. Yamamoto T, Iwasaki T, Watanabe N, Oshimi K, Naito M, Tsuruo T, et al. Expression of multidrug resistance $\mathrm{P}$-glycoprotein on peripheral blood mononuclear cells of patients with granular lymphocyte-proliferative disorders. Blood. 1993;81:1342-6.

6. Sandlund JT, Pui C-H, Mahmoud H, Zhou Y, Lowe E, Kaste S, et al. Efficacy of high-dose methotrexate, ifosfamide, etoposide and dexamethasone salvage therapy for recurrent or refractory childhood malignant Iymphoma. Ann Oncol. 2011;22:468-71.

7. Steinway SN, Leblanc F, Loughran TP Jr. The pathogenesis and treatment of large granular lymphocyte leukemia. Blood Rev. 2014;28:87-94.

8. Yamaguchi M, Kwong Y-L, Seog Kim W, MaedaY, Hashimoto C, Suh C, et al. Phase II study of SMILE chemotherapy for newly diagnosed stage IV, relapsed, or refractory extranodal natural killer (NK)/T-cell lymphoma, nasal type: The NK-cell tumor Study Group Study. J Clin Oncol. 2011; 29:4410-6.

9. Lepe-Zúñiga JL, Jerónimo-López FJ, Hernández-Orantes JG. Características citopatológicas de la leucemia aguda en el Hospital de Especialidades Pediátricas de Chiapas, México. Bol Med Hosp Infant Mex. 2017; 74:122-33.

10. Dearden C. Large granular lymphocytic leukaemia pathogenesis and management. Br J Haematol. 2011;152:273-83.

11. Suzuki R, Suzumiya J, Nakamura S, Aoki S, Notoya A, Ozaki S, et al. Aggressive natural killer-cell leukemia revisited: large granular lymphocyte leukemia of cytotoxic NK cells. Leukemia. 2004;18:763-70.

12. Lima M. Aggressive mature natural killer cell neoplasms: from epidemiology to diagnosis. Orphanet J Rare Dis. 2013;8:95.

13. Ebihara Y, Manabe A, Tanaka R, Yoshimasu T, Ishikawa K, Iseki T, et al. Successful treatment of natural killer (NK) cell leukemia following a long-standing chronic active Epstein-Barr virus (CAEBV) infection with allogeneic bone marrow transplantation. Bone Marrow Transplant. 2003;31:1169-71. 